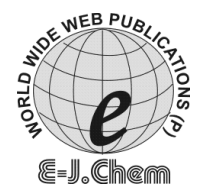

http://www.e-journals.net



ISSN: 0973-4945; CODEN ECJHAO

E-Journal of Chemistry 2009, 6(3), 681-684

\title{
Theoretical Determination of Molecular Weight of $\mathrm{AB}_{2}$ Dendrimers
}

\author{
ABDOULHOSSIEN MASSOUDI, HOOSHANG VAHEDI*, \\ OMID LOUIE and SAMI SAJJADIFFAR \\ Chemistry Department, \\ Payame Noor University (PNU), Mashhad, Iran. \\ hooshangvahedi@yahoo.co.uk
}

Received 8 July 2008; Accepted 5 September 2008

\begin{abstract}
The Molecular weight of any $\mathrm{AB}_{2}$ type dendrimers were calculated by suggested theoretical equation. The results were compared with the data reported by others. It was found that there are no remarkable differences between the calculated and reported data.
\end{abstract}

Keywords: Dendrimer, Molecular weight, Lou-Mass number collection, Generations, PPI, AMAM.

\section{Introduction}

Dendrimers are highly branched macromolecules, obtained by an interactive sequence of reaction steps, having precisely defined molecular structures ${ }^{1,3,5}$. These aesthetically appealing synthetic macromolecules distinguish themselves from normal polymers in two critical ways. Firstly, they are constructed from $A B_{n}$ monomers which produce linear polymers. Thus, they contain hyper branched structures. Secondly, they are synthesized in an interactive fashion. The combination of these two features lead to a nonlinear, stepwise synthetic growth where in the number of monomer units incorporated in each successive interaction roughly doubles $\left(\mathrm{AB}_{2}\right)$ or triples $\mathrm{AB}_{3}$.

That in the previous cycle, each repetition cycle lead to the addition of one more layer of branches which is a generation to the dendrimer from work. The generation number of the dendrimer is equal to the number of repetition cycles performed, and can be easily determined by counting the number of branch points as one proceeds from the core to the periphery ${ }^{2,4,6}$. 
In this paper, the molecular weight determination of various generations of an $\mathrm{AB}_{2}$ dendrimer were calculated for four denderimers: 1,2,4-triazole (TAZ), poly propylimine (PPI), 1,3,5-triazatriphosphinine derivative (MNBA), polyamidoamine (PAMAM) using the new suggested equation.

\section{Results and Discussion}

PPI is an $\mathrm{AB}_{2}$ type polymer, in which the core is diaminobutane. The core has two active sites $\left(Z_{0}=2\right)$, which can construct four branches for generation $1(\mathrm{G} 1)$, eight branches for generation 2(G2) and twelve branches for generation 3(G3). Lou-Mass Number Collection (LMNC) can provide the number of branches in PPI dendrimer $\mathrm{AB}_{2}$ for any generation where $n$ is the number of each generation.

$$
\mathrm{LMNC}=2 \times 2\left(2^{n}-1\right)
$$

One can generalize the above equation (1) to any type of dendrimer $\mathrm{AB}_{2}$ by taking account of active positions $\left(\mathrm{Z}_{0}\right)$ of the core to the equation (1):

$$
\mathrm{LMNC}=2 \mathrm{Z}_{o}\left(2^{n}-1\right)
$$

So, the number of the branches for any generations and for any type of dendrimer $\mathrm{AB}_{2}$ (i.e. with $\mathrm{Z}_{0}=1,2,3$ and 4) can be obtained from the equation (2) and could be illustrated as a mathematical collection (Lou-Mass Number Collection).

$$
\begin{aligned}
\mathrm{LMNC}_{Z_{0=1}} & =\{2,6,14,30,62,126, \ldots\} \\
\mathrm{LMNC}_{Z_{0=2}} & =\{4,12,28,60,124,252, \ldots\} \\
\mathrm{LMNC}_{Z_{0=3}} & =\{6,18,42,90,186,378, \ldots\} \\
\mathrm{LMNC}_{Z_{0=4}} & =\{8,24,56,120,248,504, \ldots\}
\end{aligned}
$$

The results for 6 generations of the $\mathrm{AB}_{2}$ dendrimer were outlined in Table 1 .

Table 1. The number of branches for $\mathrm{AB}_{2}$ dendrimers.

\begin{tabular}{ccccccc}
\hline$n$ & 1 & 2 & 3 & 4 & 5 & 6 \\
\hline $\mathrm{LMNC}_{Z_{0=1}}$ & 2 & 6 & 14 & 30 & 62 & 126 \\
$\mathrm{LMNC}_{Z_{0=2}}$ & 4 & 12 & 28 & 60 & 124 & 252 \\
$\mathrm{LMNC}_{Z_{0}=3}$ & 6 & 18 & 42 & 90 & 186 & 378 \\
$\mathrm{LMNC}_{Z_{0=4}}$ & 8 & 24 & 56 & 120 & 248 & 504 \\
\hline
\end{tabular}

The molecular weight of a dendrimer is the sum of the molecular weight of branches and the molecular weight of core $\left(\mathrm{M}_{\text {core }}\right)$.

$$
\begin{aligned}
& M w_{n}=M_{\text {Core }}+\left(\mathrm{LNC}_{\mathrm{Z} 0}\right) M_{r} \\
& M w_{n}=M_{\text {Core }}+2 \mathrm{Z}_{0}\left(2^{n}-1\right) M_{r}
\end{aligned}
$$

Molecular weight of the generation 1 and 3 of MNBA has reported ${ }^{7}$ which is 1052 and $5712 \mathrm{gmol}^{-1}$, respectively. By using the equation (3) and by replacing $Z_{0}=3$ for generation 1 , the amount of molecular weight would be 1026 which has $1 \%$ of deviation from the experimental data.

$$
\begin{gathered}
M_{r}=133, M_{\text {Core }}=228 \\
M w_{n}=228,+(6 \times 133)=1026
\end{gathered}
$$

Also the molecular weight for the generation 3 by using the equation (4) would be 5814 which has a $2 \%$ deviation.

$$
M w_{n}=228+2 \times 3\left(2^{3}-1\right) 133=228+(42 \times 133)=5814
$$

The fundamental structure of $\mathrm{AB}_{2}$ dendrimers with different amount of $\mathrm{Z}_{0}$ are outlined as below Figures 1-4. 


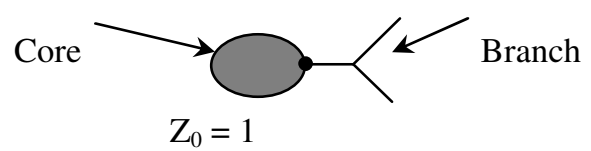

Figure 1.

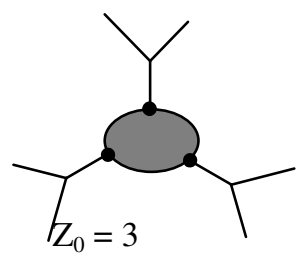

Figure 3.



Figure 2.



Figure 4.

The molecular structure of dendrimers TAZ, PPI, MNBA, PAMAM are in according to the structures in Figure 1- 4 respectively. Also, the same calculation of molecular weight was carried out for TAZ, PPI, MNBA and PAMAM and the results were summarized in Table 2.

Table 2. The reported and calculated molecular weights and percentage of error for TAZ, PPI, MNBA,PAMAM dendrimer

\begin{tabular}{|c|c|c|c|c|c|}
\hline \multicolumn{2}{|c|}{ Dendrimer } & Generation & $\begin{array}{c}\text { Molecular } \\
\text { Weight reported } \\
\end{array}$ & $\begin{array}{c}\text { Calculate } \\
\text { Molecular Weight } \\
\end{array}$ & $\begin{array}{c}\text { Error } \\
\text { percent, }\end{array}$ \\
\hline \multirow{3}{*}{$\begin{array}{l}\text { TAZ } \\
\mathrm{Z}_{0}=1\end{array}$} & $\mathrm{M}_{\text {core }}=174$ & $\mathrm{G}_{1}$ & $584^{13 a}$ & 584 & 0.0 \\
\hline & $\mathrm{M}_{\mathrm{r}}=205$ & $\mathrm{G}_{2}$ & $1404^{13 a}$ & 1312 & 7.0 \\
\hline & $\begin{array}{c}M_{\text {core }}=159 \\
M_{r}=205\end{array}$ & $\mathrm{G}_{1}$ & $571^{13 b}$ & 569 & 0.35 \\
\hline PPI & $\mathrm{M}_{\text {core }}=84$ & $\mathrm{G}_{1}$ & $316^{8}$ & 316 & 0.0 \\
\hline \multirow[t]{5}{*}{$\mathrm{Z}_{0}=2$} & $\mathrm{M}_{\mathrm{r}}=58$ & $\mathrm{G}_{2}$ & $773^{8}$ & 780 & 0.9 \\
\hline & & $\mathrm{G}_{3}$ & $1687^{8}$ & 1708 & 1.2 \\
\hline & & $\mathrm{G}_{4}$ & $3514^{8}$ & 3564 & 1.4 \\
\hline & & $\mathrm{G}_{5}$ & $7168^{8}$ & 7276 & 1.5 \\
\hline & & $\mathrm{G}_{5}$ & $7140^{12}$ & 7276 & 1.9 \\
\hline MNBA & $M_{\text {core }}=228$ & $\mathrm{G}_{1}$ & $1052^{7}$ & 1026 & 2.5 \\
\hline $\mathrm{Z}_{0}=3$ & $\mathrm{M}_{\mathrm{r}}=133$ & $\mathrm{G}_{3}$ & $5712^{7}$ & 5814 & 1.8 \\
\hline \multirow{4}{*}{$\begin{array}{c}\text { PAMAM } \\
\mathrm{Z}_{0}=4\end{array}$} & $M_{\text {core }}=516$ & $\mathrm{G}_{1}$ & $1430^{11}$ & 1436 & 2.1 \\
\hline & $\mathrm{M}_{\mathrm{r}}=115$ & $\mathrm{G}_{3}$ & $6909^{11}$ & 6956 & 0.7 \\
\hline & & $\mathrm{G}_{5}$ & $28824^{11}$ & 29036 & 0.7 \\
\hline & & $\mathrm{G}_{6}$ & $58047^{11}$ & 58476 & 0.74 \\
\hline
\end{tabular}

As it is apparent from the table the inaccuracy of the molecular weight by comparing with those of Table 2 are trivial. It is interesting that with taking out of two continues $\mathrm{LMNCz}_{0}$ from the Table 1, one can find out the surface branch of the higher generation according to those reported by Newkome ${ }^{1,9,10}$. The surface branches are shown in Table 3 .

Table 3. The number of surface branches for $\mathrm{AB}_{2}$ dendrimers.

\begin{tabular}{ccccccc}
\hline Number of surface branch & \multicolumn{6}{c}{ Generation, $\mathrm{n}$} \\
\cline { 2 - 7 } & 1 & 2 & 3 & 4 & 5 & 6 \\
\hline $\mathrm{Z}_{0=1}$ & 2 & 4 & 8 & 16 & 32 & 64 \\
$\mathrm{Z}_{0}=2$ & 4 & 8 & 16 & 32 & 64 & 128 \\
$\mathrm{Z}_{0=3}$ & 6 & 12 & 24 & 48 & 96 & 192 \\
$\mathrm{Z}_{0}=4$ & 8 & 16 & 32 & 64 & 128 & 256 \\
\hline
\end{tabular}




\section{Conclusions}

The molecular weight of any $\mathrm{AB}_{2}$ type dendrimers were calculated by suggested theoretical equation and compared to those reported. It was found that there are no remarkable differences between the calculated and reported data.

\section{Acknowledgment}

Authors are grateful to Payame Noor University (PNU) for receiving financial support.

\section{References}

1. Newkome G R and Shreiner C D, Polymer, 2008, 49, 1-173.

2. Massoudi A H and Maddahi A, Asian J Chem., 2008, 20, 1, 463-467.

3. Van der Wal S, Mengerink Y and Brackman J C, J Chromatogr A., 1998, 825, 135-147.

4. Weener J W, Van Dongen J L J and Meijer E W, J Am Chem Soc., 1999, 121, 1035.

5. Eric G, Osterom O, Reek J M H, Paul C, Kamer Y and Van Leeuwen P W N M, Angew Chem Int Ed., 2001, 40, 1828-1849.

6. Zeng S and Zimmerman C, Chem Rev., 1997, 97, 1681-1712.

7. Servin P, Cyrille R, Re'gis L, Peruzzini M, Caminade A M and Majoral J P, Tetrahedron Lett., 2007, 48, 579-583.

8. Tasdelen M.A, Demirel A L and Yagci Y, European Polymer J., 2007, 43, 4423-4430.

9. Faul C F J, Antonietti M, Hentze H P and Smarsly B, Physicochem Eng Aspects, 2003, 212, 115-121.

10. Zhang W, Xie J and Shi W, Eur Polymer J., 2007, 43, 2387-2400.

11. Han, M, Chen P and Yang X, Polymer, 2005, 49, 3481-3488.

12. Jain, N K and Singh H, J Pharm Pharmaceut Sci., 2007, 10(3), 358-367.

13. Maes W Verstappen B and Dehaen W, Tetrahedron, 2006, 62, 2677-2683. 




International Journal of

Medicinal Chemistry

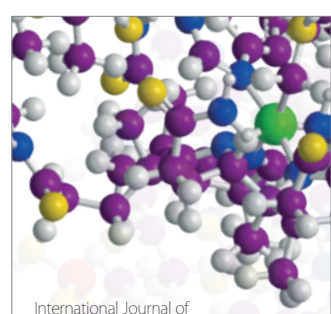

Carbohydrate Chemistry



The Scientific World Journal
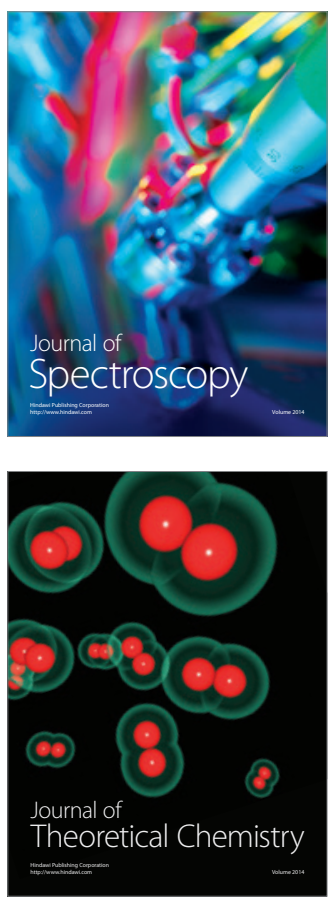
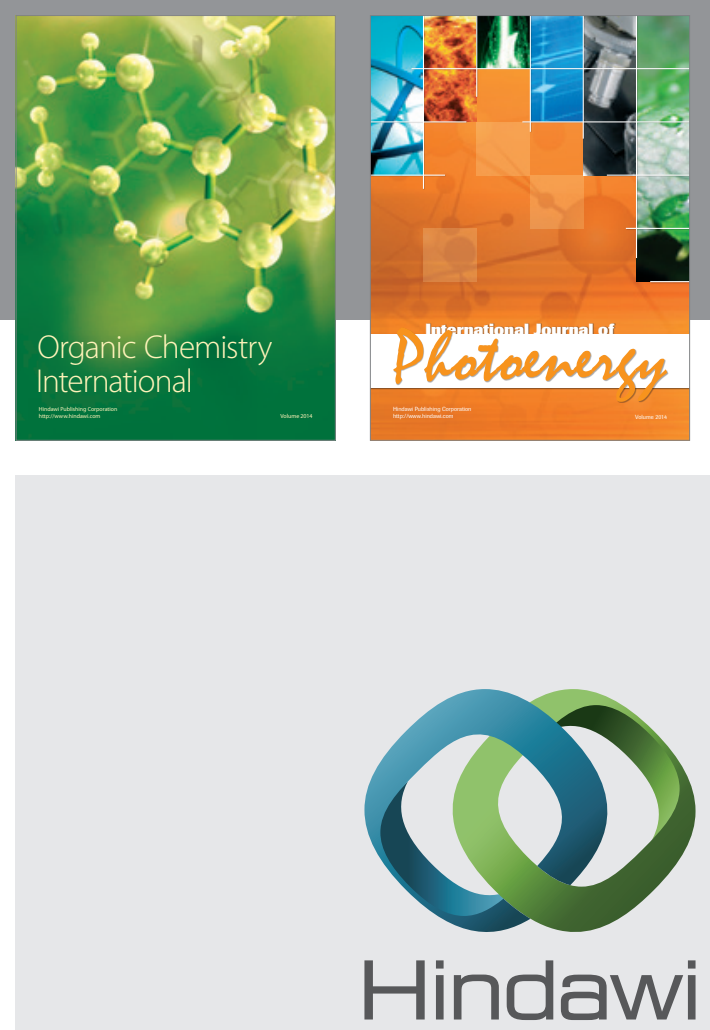

Submit your manuscripts at

http://www.hindawi.com
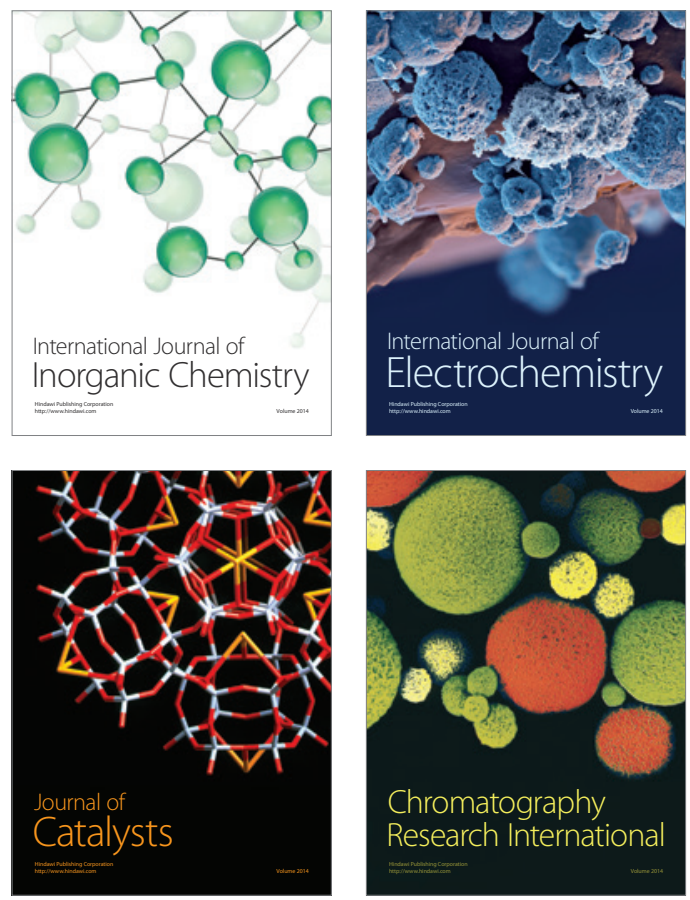
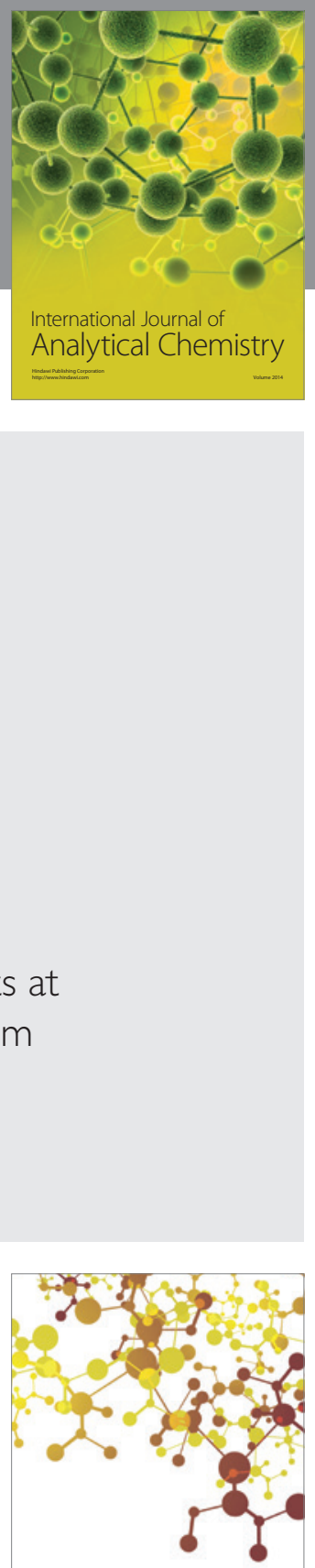

Journal of

Applied Chemistry
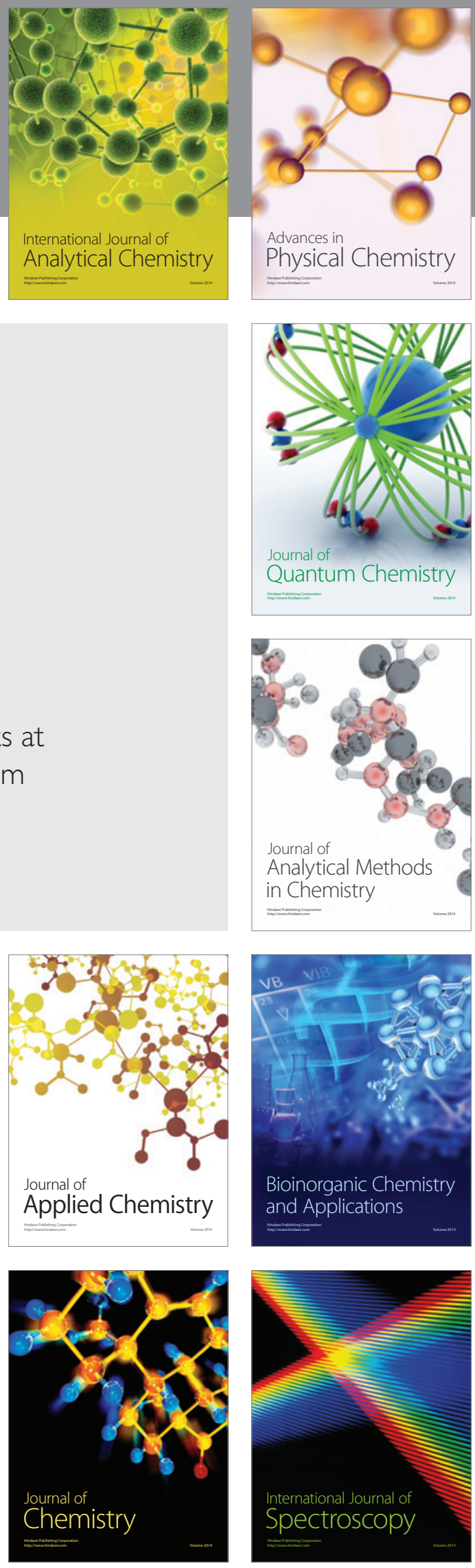